\title{
Research on Safety Management System of University Laboratory
}

\author{
W.B. Zhu, H.X. Liu, T. Jin \\ Office of Educational Administration \\ Tianjin Agricultural University \\ Tianjin, China
}

\author{
L. Huang \\ College of Agronomy \& Resources and Environment \\ Tianjin Agricultural University \\ Tianjin, China
}

\author{
J. Liu, X. Sun* \\ College of Biological Engineering \\ Tianjin Agricultural University \\ Tianjin, China \\ *sunxiaoxisunxiao@163.com
}

\begin{abstract}
Laboratory is an important part in colleges and universities teaching and scientific research. It's necessary to strengthen management to smooth the experimental teaching activities, and ensure the safety of teachers and students. This article discussed the respects of laboratory safety management responsibility system, laboratory safety management training system, chemical drug use management system, and the safety protection system and safety supervision mechanism constructing laboratory safety management system, in order to improve the level of the college laboratory safety administration for reference.
\end{abstract}

Keywords-laboratory; safety; management system

\section{IMPORTANCE OF LABORATORY SAFETY MANAGEMENT SYSTEM CONSTRUCTION}

Lab is an important base for teaching and research in universities, and chemical reagents are necessary for analysis and experiment procedure [1]. Consumption of chemical reagents multiplied because of the yearly increase of university enrollment, cultivation of students' experimental skills, increase of new experiment. Laboratory offers a wide range of chemical reagents, different in specifications and dosages, and different levels of poisonousness and danger, to strengthen the management is not only the need of the experimental teaching, but also the need to ensure the safety of teachers and students. At the same time, a string of movements such as management, collection, storage, transportation, and processing to laboratory waste(including chemical waste, spent liquor, remains of dead plants and animals, microbial pathogens, etc.) also need to be highly focused by the related departments, due to the improper handling will cause serious environmental pollution and even personal injuries [2].

\section{CONSTRUCTION OF LABORATORY SAFETY MANAGEMENT SYSTEM}

In order to ensure the safe operation of the university laboratory, there must be a standardized and scientific safety management system, comprehensive security from these five aspects---responsibility system, training system, the usage management systems, protection systems and supervision system.

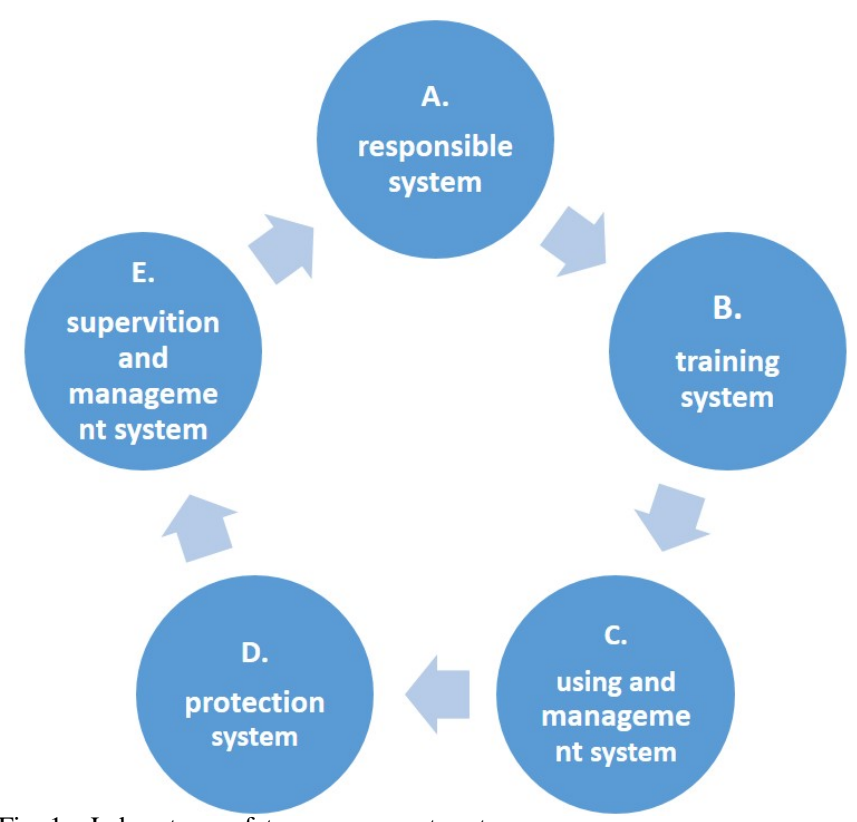

Fig. 1. Laboratory safety management system.

\section{A. Responsibility System of Experimental Safety Management}

School Comprehensive Management Committee, which is led by principal, composed of security department, the general department, the state property department, dean's office ,as well as experts from the chemical, biological, environmental safety and other fields, is responsible for the overall management of laboratory safety; each secondary college deans is fully responsible for the safety of the affiliated labs, designing suitable management regulations and guidebook to laboratory safety, hazardous chemicals and waste management ,regularly organizing laboratory safety technical guidance and training, emergency response process drills to 
ensure each laboratory has a complete security management system[3]. Each school dean should sign a laboratory security responsibility regularly with laboratory directors and safety officer to allot responsibility to individuals. Every student or staff newcomer should be trained about the safety operation of experiment, waste classification storage method, hazardous waste category, protection and emergency treatment. Only if they pass the assessment can carry out experiments. The school must organize a compulsory fire team, regularly planning fire drills to ensure timely response if labs caught fire.

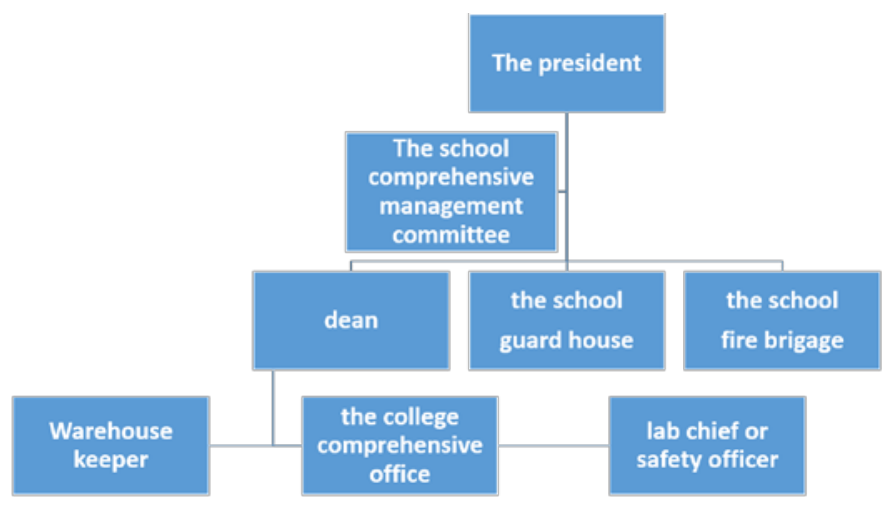

Fig. 2. Safety management responsibility system

\section{B. Training System of Laboratory Safety}

To strictly implement the laboratory safety training system, every school should develop a safe course for undergraduate and graduate students, required to pass the exams before entering the labs, and new staffs are asked to do likewise [4]. Each semester, laboratory personnel should be training further to strengthen security concept. In addition, security book corner is set in each lab in order to popularize the security commonsense.

Taking advantage of existing network platform, "laboratory safety education" courses "E - learn" system are introduced for "laboratory safety education", the system includes the following main function modules:

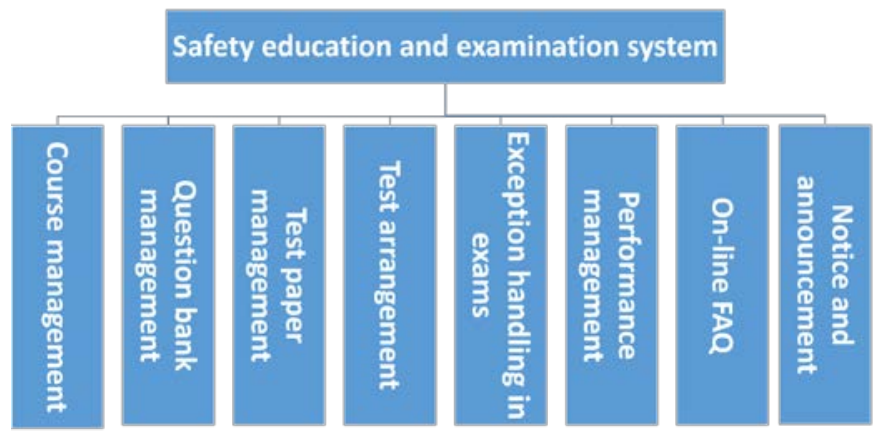

Fig. 3. Safety education and examination system

Course management: courses like radiation safety, electrical safety, biomedical safety, chemical safety, general security are included. The administrator can add and modify the knowledge in some chapters, and upload the related courseware to make students use their free time autonomous learning online[5].

Question bank management: the question bank contains all the knowledge in the course management module. According to the inspection requirements, the administrator can rectify and add the answers to the test questions. Topic types including general class, chemical safety, biological, medical, electrical safety, radiation safety class, etc. have been collected[6].

Test paper management: The test paper can be set directly by computer. Such as course name, type of the test paper, name of test paper, purpose of the test paper, test scores, pattern of the questions, the total times allowed to take the exam, and whether to display the exam score on the paper.

Test arrangement: the test information can be edited autonomously, such as the test time, test type (offline or online), the passing score, the answer pattern (the whole volume or one by one question), test papers, whether to allow to check the performance (pass or failure), the effective time of the paper. You also can select the range of the students or teachers, set the examination personnel list[7].

Exception handling in exam and performance management: these models are used for administrators to conveniently and autonomously manage test procedure, students and scores through the computer.

Online FAQ: It promotes the communication about laboratory safety between teachers and students.

The system takes advantage of the fast and flexible network platform, getting rid of the classroom education mode. Teachers can upload the courseware directly to the network platform, combining with the systematic laboratory safety knowledge to open "experimental safety education" courses for the students. Students use their time learning laboratory safety knowledge autonomously, at the same time, the system will automatically give students their learning information, including the number of students' online learning, learning times, learning duration. In addition, teachers can organize students to take online examination, after the test, the system automatically give the test times, the number of students, test scores, grade point average, percent of pass and excellence, etc.

The platform of laboratory safety course not only can be used for the students, also can be used for the laboratory teachers and the preservice training to scientific research personnel. The development of this platform will greatly save the input of safety education time and personnel. It means that more time will be used to learn professional knowledge. At the same time, students can complete safety knowledge learning and practice in the dormitory, which can stimulate students' interest in learning, improve their participation, and ease laboratory safety knowledge learning and assessment. Therefore, the biotechnology experiment safety platform taking advantage of the Internet is the supplement of traditional teaching mode. It has great value to promote the education informatization construction, improve the students' laboratory safety consciousness, and ensure the safety of the experiment teaching activities. 


\section{The Chemical Usage Management System}

Particular staffs are in charge of obtaining chemical reagent, account management, warehouse safety and other work. Teachers can get chemical lists and stock information online, meanwhile they directly complete booking, order, return and other matters online.1-2weeks before the laboratory class, teacher need to make an application to administrator. If chemicals needed are in stock, you can directly get them; if there is no inventory, the administrator should order timely to ensure experiments run smoothly. In addition, teachers return the remaining supplies and medicines to warehouse, so that not only improve the utilization of drugs, but also reduce risks of excessive piling in laboratory. In particular, laboratory waste recycling and dispose should be well done, which means school must have a clear laboratory waste chemicals and spent liquor disposal procedures, establish a regular laboratory waste recycling system, and the laboratory director regularly send hazardous waste to the designated location.

\section{Security Protection System in the Laboratory}

There must be complete protection and health care equipment, mainly including emergency sprinkler, protective glasses, protective gloves, wash eyes, laboratory emergency kit, ventilation cabinet (variable air volume control system), and exhaust reagent cabinet. Furthermore, faculty offices and student study rooms must be separated with laboratory.

\section{E. Laboratory Safety Supervision and Management Mechanism}

Each laboratory should establish a strict laboratory safety supervision mechanism, strictly implementing the routine safety inspections and unscheduled inspections, making a record, a comprehensive health and safety check on the eve of public holidays and summer vacation, carrying out the yearend safety summary and security reward system.

\section{EMBODIMENTS OF LABORATORY SAFETY MANAGEMENT SYSTEM}

\section{A. Deepening Curriculum Reform}

Teaching reforms with the core of curriculum system are deepened, including preparation the universality, targeted environmental safety education materials. School related departments combined to form compulsory measures, people consider laboratory safety education assessment as hard conditions, in order to promote laboratory safety training and education. Access to training, regular training, emergency drills combined, various forms of safety education are performed to all the students and teachers.

Actively promote green chemistry, construct environmentfriendly labs, control waste and pollution from the source. For example: Use non-toxic reagent (substitute for benzene, mercury, mercury salts, chloroform, etc.); minimize the use of toxic and hazardous chemical agent, or perform a small amount of semi-micro type experiment; recycling, purification and reuse are necessary (chemicals as benzene, ether, petroleum ether, acetone, etc.); dangerous gas emissions after going through the absorption device (chlorine, concentrated hydrochloric acid, ammonia, etc.).

\section{B. To Create Environmentally Safe Atmosphere}

Strengthening safety education and publicity and carrying out several of safety activities aim to create an atmosphere on campus that is a "Safety is everyone's responsibility", improve the overall safety awareness among teachers and students. There is no doubt that a safety atmosphere on campus is the best way to promote safety awareness of staff and students.

A string of activities, such as advocacy, lectures on safety, accident case studies, Safety Day, safety week; laboratory safety training, communication, seminars and security knowledge competition can help involve more teachers, students and other staff to popularity the lab safety culture in campus.

\section{Good Laboratory Personnel Management}

Each laboratory director should do a good job managing the laboratory personnel, strictly enforcing access training that newcomers must get the lab safety education before entering the laboratory. Regular training is essential ---every semester laboratory personnel need to be further safety trained, to strengthen their security concept. There must be a explicit assessment system, considering the laboratory personnel safety assessment as an important part of the laboratory assessment. A complete security laboratory personnel performance appraisal system is combined with rewards and punishments.

\section{CONCLUSION}

Laboratory is the birthplace of new technology, often full of hardships and dangers. Life is serious. In the journey of exploration, with the security insurances, we can explore the mysteries of the scientific world better. Life is priceless, safety first. This article discussed the establishment of the laboratory safety management system from safety management responsibility system, laboratory safety management training system, chemical drug use management system, and the safety protection system and safety supervision mechanism. At the same time, through deepening the reform of the experimental curriculum system, striving to create a safe and environmentally friendly campus atmosphere and strict management of laboratory personnel and other measures, the level of laboratory safety management in Colleges and universities can be effectively improved.

\section{REFERENCES}

[1] B.H. Huang, "Research on the Management of the Laboratory in Colleges and Universities Based on the Construction of Experiment Teaching Demonstration Center,” Experiment Science and Technology, vol.26, pp.94-97, 2009.

[2] J. Cheng, F. Gao, "Exploration and Reflections on Construction of Experimental Teaching Centre in Colleges and Universities,” Research and Exploration in Laboratory, vol.31, pp.101-102, 2012.

[3] Z.X. Luo, "Construction and Thought on Model Experiment Teaching Center,” Experiment Science and Technology, vol.6, pp.1-3, 2008. 
[4] L.B. Song, Z.L. Xiao, J.L. Zeng, "Discussion on Construction of Experimental Teaching Demonstration Centers in Local Colleges," Experiment Science and Technology, vol.11, pp.116-118, 2013.

[5] W.J. Feng,L.Q. Liao,G. Zhu, Practice and Thought on Building the Mechanical Experiment-Teaching Model Center, Experiment Science \& Technology, 2008.

[6] J.Chen, J Zou,Z. Chen, Research and practice of construction of experiment teaching center of architecture speciality, Experimental Technology \& Management, 2011.

[7] L. Wang,Z. Wang,G.U. Yi-Huang, Construction and thought on rehabilitation experimental teaching center of traditional Chinese and western medicine, China Higher Medical Education, 2011. 